Jurnal Keperawatan Padjadjaran

ISSN 2338-5324 (print)

ISSN 2442-7276 (online)

Online di http://jkp.fkep.unpad.ac.id

DOI : $10.24198 / \mathrm{jkp}$

\title{
The Effect of Combination of Buteyko Breathing Technique and Walking Exercise on Forced Peak Expiratory Flow In Adult Asthmatic Patients
}

\author{
Wiwik Udayani ${ }^{1}$, Muhammad Amin ${ }^{2}$, Makhfudli ${ }^{1}$ \\ ${ }^{1}$ Faculty of Nursing, Universitas Airlangga, Surabaya, Indonesia \\ ${ }^{2}$ Faculty of Medicine, Universitas Airlangga, Surabaya, Indonesia \\ Corresponding email: wiwikudayani2008@gmail.com
}

Submitted: 24-06-2019 Accepted: 13-08-2019 Published: 14-08-2019

\begin{abstract}
The Buteyko technique can reduce asthma symptoms, reduce the use of bronchodilators but few and not significant in reducing bronchial responsiveness. Physical exercise that complements breathing exercises in pulmonary rehabilitation can improve pulmonary physiology and control asthma. Physical exercise in the form of walking can improve pulmonary physiology and asthma control by reducing hyperesponsivity reactions and increasing cardiorespiratory endurance. But the combination of these two exercises has never been studied. The objective of this study was to analyze the effect of a combination of Buteyko breathing techniques and walking exercises on Peak Forced Expiration Flow. The design of this study was quasi experimental with pretest-posttest control group design. The location of the study was in the pulmonary clinic of Regional General Hospital of Sidoarjo Regency and Bangil Regional General Hospital in Pasuruan Regency, East Java. Respondents were selected by randomization by simple random sampling. Respondents in this study amounted to 76 respondents. Forced Expiration Peak Flow Data is measured using a peak flow meter. The intervention group was given a combination exercise with Buteyko breathing technique and walking exercise for 8 weeks, 3x per week, 55 minutes every training session. Giving a combination of Buteyko breathing technique and walking exercises using module and video media. FPEF measurements were carried out 3 times (pretest, week 4, week 8). Data were analyzed using SPSS 22 with GLM-RM (General Linear Model-Repeated Measure) ANOVA. The results showed a significant difference in the FPEF rate between before and after 4 weeks and 8 weeks of the combination intervention of the Buteyko breathing technique and walking exercises in the treatment group with $(\mathrm{p}<0.05)$ with $\mathrm{p}=0.000$. The findings indicate that breathing exercises and physical exercise through a combination of Buteyko breathing techniques and walking exercise can increase the FPEF rate through the mechanism of increasing CO2 and producing nitric oxide which has bronchodilation effects and through decreasing inflammatory mediators so that it can reduce asthma symptoms. This exercise can be used as an alternative choice in supporting pharmacological therapy to improve FPEF.
\end{abstract}

Keywords: Asthma, asthma control, buteyko, forced expiration peak flow (FPEF), walking exercise. 
Wiwik Udayani: The Effect of Combination of Buteyko Breathing Technique and Walking Exercise

\section{Introduction}

Chronic respiratory disease, one of them is asthma, is a major public health problem and will remain a challenge for the future but this disease still receives minimal attention and care (Renolleau-Courtois et al., 2014). One of the pulmonary function impairments is Forced Peak Expiration Flow in patients with asthma due to airway obstruction and weakness of respiratory muscles as a result of frequent inflammatory processes, dipsnea and the presence of obstacles in activity (Sahat, Irawaty and Hastono, 2011). The prevalence of asthma in the world is estimated at 334 million people of all ages (Phillips, 2014) and an estimated 235 million people live with asthma and countries with middle to lower income are about $80 \%$ of asthma associated with death (WHO, 2018) . In 2025 it is estimated that the prevalence of asthma in the world has increased to reach 400 million people (Masoli et al., 2004). Whereas according to Basic Health Research in 2013 asthma in Indonesia ranks highest for the non-communicable disease category of $4.5 \%$ and in East Java the prevalence of asthma is $5.1 \%$.

Pharmacological management of asthma is very useful in the event of an asthma attack. The disadvantage of using longterm pharmacological therapy is that it has side effects especially if it does not control treatment (Ducharme dan Hicks, 2000). Asthma patients who do not do breathing exercises regularly can aggravate the symptoms of shortness of breath that arise during an attack because these patients do not know the correct breathing technique. This can cause ventilation-perfusion imbalance in the lungs. Breathing training and physical activity or exercises that are not carried out by asthma patients have an impact on the weakness of the respiratory muscles so that there is a decrease in lung function, in addition to respiratory disorders and symptoms of shortness of breath will increase and tolerance to activity decreases (Sahat, Irawaty and Hastono, 2011).

Nonpharmacological management can be done through physical activity and breathing training (GINA, 2018). Physical exercises that complement breathing training in pulmonary rehabilitation can improve lung function and control asthma (Juhariyah et al., 2012). Breathing training recommended for asthma is Buteyko breathing technique (Godfrey, 2010). A study conducted by Mohamed, Riad dan Ahmed (2013) showed that Buteyko breathing technique could increase the Forced Expiration Peak Flow and control of asthma. The advantage of Buteyko breathing technique is the control pause which can reduce excessive $\mathrm{CO} 2$ expenditure which will regulate breathing through the medulla respiratory center, producing nitric oxide (NO) which has bronchodilating effects. Walking exercises can improve lung function and control asthma by reducing hypersensitivity reactions and increasing cardiorespiratory endurance (Pakhale et al., 2013). The objective of the study is to analyze the effect of a combination of Buteyko breathing techniques and walking exercises on Peak Forced Expiration Flow.

\section{Method}

The design of research was quasi-experimental with pretest-posttest control group design. APEP values were measured in the pretest and post-test twice, on 4th week and 8th week. The treatment group was given a combination of Buteyko breathing techniques and walking exercises for 8 weeks conducted independently at home. Before intervening independently at home, respondents were given a combination training in Buteyko breathin technique and walking exercise using media module training and video.

The steps of the Buteyko breathing technique:

1) Sit up straight and try to position as comfortable as possible, then start breathing normally through the nose.

2) Hold your breath until you first feel the desire to breathe then release the pinch on the nose, then start breathing gently through the nose.

3) Then sit in a comfortable position with your back straight and feet and knees shoulder width apart, then close your eyes. then start breathing normally and calmly through the nose.

4) Then take a break for 20-30 seconds 
Wiwik Udayani: The Effect of Combination of Buteyko Breathing Technique and Walking Exercise

5) Repeat actions 2 and 3 for 3 minutes.

6) Then take a short rest for 20-30 seconds.

7) Repeat actions 2 and 3 for 3 minutes.

8) Then take a short rest for 20-30 seconds.

9) Repeat actions 2 and 3 for 3 minutes

10) Then take a long rest for 2 minutes.

11) Repeat action 2

The steps of walking exercise:

Walking exercises are carried out at temperatures that are not too cold or hot or between 6-8 o'clock in the morning and are carried out in an environment free of air pollution

1. Warm up for 5 minutes by moving or stretching a group of muscles, such as head muscles, arms, back, and legs

2. Perform 30 minutes of continuous walking or continuous exercise with relaxation or relaxation. Do it walking on a flat surface (Renolleau-Courtois et al., 2014).

3. Walking exercises are done by adjusting the speed yourself to be comfortable and do not get tired or tight.

4. Exercise is stopped if the patient feels breathing too fast and deeply.

5. Training can be resumed if you have a wife and feel comfortable.

6. Cooling down for 5 minutes by stretching slowly in the leg and hand muscles

Researchers taught how to assess exercise tolerance, which is $60-80 \%$ maximum heart rate. Maximum heart rate calculation using the 220-age. Assessment of tolerance limits is carried out every 6 minutes during walking exercise.

The exercises which included Buteyko breathing technique were carried out for 15 minutes, the walking exercise for 40 minutes ( 5 minutes warming up, 30 minutes walking, 5 minutes cooling-down) so that the total exercise was 55 minutes. Exercise was done 3 times a week for 8 weeks. The researcher made a home visit every $1 \mathrm{x} /$ week to evaluate the accuracy of the exercise being carried out and the development patient's condition. The potential danger in doing this exercise is the low category because the intensity of the exercise is adjusted to the ability of the respondent. Potential danger that can occur was exercise induce asthma. If exercise induce asthma occurs that is fatigue, tightness, increased breathing effort, cough, the respondent can rest 50-10 minutes and exercise can be resumed if the respondent feels relaxed and comfortable. If the sign and symptom of exercise induced asthma does not decrease or persist with rest, respondents can use pharmacological therapy bronchodilator spray class SABA (Short Acting Beta 2 Agonist), reliever that has been given a pulmonary specialist at the Pulmonary Clinic. Researchers also provided respondents with a small portable oxygen supply that could be used during exercise if tightness arises. Patients in the intervention group and the control group continued to carry out pharmacological therapy from the Lung Specialist doctor at the Pulmonary Clinic Poly Hospital. If with the above procedure the condition of the respondent does not improve, the family can deliver the respondent to the nearest hospital emergency room to get emergency treatment.

The researcher recommended the respondent to fill out the exercise checklist format according to the training schedule. The researcher reminded respondents both by telephone, sms, and social media to do the exercises independently according to the direction of the researcher. The researcher also involved the respondent's family in reminding respondents to do the exercises. The treatment group was conducted at the pulmonary Clinic in the Regional General Hospital of Sidoarjo Regency. All respondents in this study continue to undergo asthma treatment and the selected respondents are asthma patients who have never taken breathing exercises or physical training for asthma patients. The control group was not permitted to do breathing exercises and other physical exercises but they had the right and permission do breathing exercises and or other physical exercises during the study but respondents will be included in the drop out criteria.The control group was conducted at the Pulmonary Clinic in the Bangil Regional General Hospital in Pasuruan Regency.

The population in this study were adult patients with asthma by respirologist in the the pulmonary clinic of Regional General Hospital of Sidoarjo Regency and Bangil Regional General Hospital in Pasuruan Regency by using history taking, physical examination, and spirometry tests. 
Wiwik Udayani: The Effect of Combination of Buteyko Breathing Technique and Walking Exercise

The sample in this study was taken from the population with inclusion and exclusion criteria, such as:

1. Inlusion criteria

1) Asthma patients aged 18-60 years.

2) Stable asthma

3) Good hearing and vision function

4) Having a physical and mental health

5) Patients have never participated in breathing exercises and or physical exercise

2. Exclusion criteria

1) Smoking patients

2) Asthma patients who are obese

3) Asthma in pregnancy

4) Having other pulmonary diseases such as pulmonary TB, COPD, pulmonary carcinoma

5) Having hypertension, heart

failure, epilepsy,

musculoskeletal disorders

3. Drop out criteria

1) Respondents did breathing

exercises and other physical

exercises during the study

2) Respondents did not complete the

intervention phase

3) Respondents resigned for various reasons

4) Respondents who experienced

recurrence during training

The sample technique used probability sampling with simple random sampling. The sample size was obtained through a large sample formula for hypothesis testing different proportions of 2 groups of data pairs (Dahlan, 2013). The sample size in this study was 38 respondents for the treatment group and 38 respondents for the control group. Samples were taken using Measurement of Peak Forced Expiration Flow using a wright standard peak flow meter.

Measurements of Peak Forced Discharge performed using a peak flow meter carried out on the morning before 7 before the use of bronchodilator or 6 hours after the use of bronchodilators, the researcher gave one disposable mouthpiece for one measurement. The stages in carrying out FPEF measurements using a peak flow meter according to Adeniyi and Erhabor (2011), were :

1) Install the mouthpiece to the tip of the peak flow meter

2) Position the patient to stand or sit with his back upright and hold the peak flow meter horizontally without touching or disturbing the marker movement. Make sure the marker is in the lowest scale position (zero)

3) Encourage the patient to breathe as deep as possible, put it in the mouth

4) With the lips close tightly around the mouthpiece, exhale immediately as strong as possible

5) When exhaling, the marker moves and shows the number on the scale, noting the results.

6) Return the marker to zero position and repeat steps 2-4, 3 times, and select the highest value.

7) Compare this value with the previous patient's best value or predictive value.

Statistical tests using the General Linear Model-Measured Measured ANOVA within subjects to determine the difference in Peak Forced Examination values pre-test and posttest in each group. General Linear ModelMeasured Measured ANOVA between subjects was used for showing effect of the combination of Buteyko breathing technique and walking exercise on FPEF between treatment groups and control groups (Dahlan, 2014). The researcher did not put covariate (age, sex, education, Body Mass Index) in statistical test.

Ethical approval was issued by the Health Research Ethics Committee (KEPK) of Sidoarjo Regency Hospital with Number: $893.3 / 0332 / 438.6 .7 / 2019$ and by the Health Research Ethics Team of Bangil Hospital Pasuruan Regency with Number: 445.1/570.2/424.202/2019

\section{Results}

Table 1 shows that the age characteristics of respondents in the treatment group were almost partially in the age range of 36-45 years, namely $17(44.7 \%)$ while in the control group more than half of the respondents were in the age range of 46-60 years ie $22(57.9 \%)$ 
Wiwik Udayani: The Effect of Combination of Buteyko Breathing Technique and Walking Exercise

Table 1 Respondent's characteristic

\begin{tabular}{|c|c|c|c|c|c|}
\hline \multirow[t]{2}{*}{ Characteristic } & \multicolumn{2}{|c|}{ Treatment Group } & \multicolumn{2}{|c|}{ Control Group } & \multirow[t]{2}{*}{$\mathbf{p}$} \\
\hline & f & $\%$ & f & $\%$ & \\
\hline \multicolumn{6}{|l|}{ Age (Years) } \\
\hline $18-25$ & 1 & 2.6 & 1 & 2.6 & 0.510 \\
\hline $26-35$ & 8 & 21.1 & 7 & 18.4 & \\
\hline $36-45$ & 17 & 44.7 & 8 & 21.1 & \\
\hline $46-60$ & 12 & 31.6 & 22 & 57.9 & \\
\hline Total & 38 & 100 & 38 & 100 & \\
\hline \multicolumn{6}{|l|}{ Sex } \\
\hline Male & 10 & 26.3 & 13 & 34.2 & 0.144 \\
\hline Female & 28 & 73.7 & 25 & 65.8 & \\
\hline Total & 38 & 100 & 38 & 100 & \\
\hline \multicolumn{6}{|l|}{ Education } \\
\hline Junior High School & 3 & 7.9 & 17 & 44.7 & 0.098 \\
\hline High School & 13 & 34.2 & 12 & 31.6 & \\
\hline College & 22 & 57.9 & 9 & 23.7 & \\
\hline Total & 38 & 100 & 38 & 100 & \\
\hline \multicolumn{6}{|l|}{ Occupation } \\
\hline Private & 8 & 21.1 & 6 & 15.8 & 0.574 \\
\hline Enterpreneur & 8 & 21.1 & 8 & 21.1 & \\
\hline Civil Servant & 15 & 39.5 & 9 & 23.7 & \\
\hline $\begin{array}{l}\text { Others (Housewife, } \\
\text { student, retiree) }\end{array}$ & 7 & 18.4 & 15 & 39.5 & \\
\hline Total & 38 & 100 & 38 & 100 & \\
\hline \multicolumn{6}{|l|}{ Body Mass Index } \\
\hline Underweight: $\leq 18.5$ & 2 & 5.3 & 4 & 10.5 & 0.267 \\
\hline Normal: 18.6-24.9 & 18 & 47.4 & 13 & 34.2 & \\
\hline Overweight: $25-29.9$ & 18 & 47.4 & 21 & 55.3 & \\
\hline Total & 38 & 100 & 38 & 100 & \\
\hline \multicolumn{6}{|c|}{ Family history of Asthma } \\
\hline Yes & 32 & 84.2 & 34 & 89.5 & 0.504 \\
\hline No & 6 & 15.8 & 4 & 10.5 & \\
\hline Total & 38 & 100 & 38 & 100 & \\
\hline
\end{tabular}

Table 2 Forced Peak Expiration Flow Data Distribution (\%) Treatment Groups and Control Groups

\begin{tabular}{lcccccccccccc}
\hline \multirow{2}{*}{$(\%)$} & \multicolumn{4}{c}{ Treatment Group } & \multicolumn{1}{c}{ Control Group } \\
\cline { 2 - 13 } & $\begin{array}{c}\text { Pre } \\
\text { test }\end{array}$ & \% & $\begin{array}{c}\text { 4th } \\
\text { week }\end{array}$ & $\%$ & $\begin{array}{c}\text { 8th } \\
\text { week }\end{array}$ & \% & $\begin{array}{c}\text { Pre } \\
\text { test }\end{array}$ & \% & $\begin{array}{c}\text { 4th } \\
\text { week }\end{array}$ & \% & $\begin{array}{c}\text { 8th } \\
\text { week }\end{array}$ & \% \\
\hline $80-100$ & 5 & 13.2 & 7 & 18.4 & 10 & 26.3 & 5 & 13.2 & 4 & 10.5 & 4 & 10.5 \\
$50-80$ & 17 & 44.7 & 21 & 55.3 & 20 & 52.6 & 16 & 42.1 & 18 & 47.4 & 17 & 44.7 \\
$\leq 50$ & 16 & 42.1 & 10 & 26.3 & 8 & 21.1 & 17 & 44.7 & 16 & 42.1 & 17 & 44.7
\end{tabular}


Wiwik Udayani: The Effect of Combination of Buteyko Breathing Technique and Walking Exercise

\begin{tabular}{lllllllllllll} 
Total & 38 & 100 & 38 & 100 & 38 & 100 & 38 & 100 & 38 & 100 & 38 & 100 \\
\hline
\end{tabular}

Table 3 Forced Peak Expiration Flow value ( $\mathrm{L} / \mathrm{min}$ ) in the treatment and control groups

\begin{tabular}{|c|c|c|c|c|}
\hline Group & Time & Mean \pm SD & Average difference & p-value \\
\hline \multirow[t]{3}{*}{ Treatment } & Pre vs $4^{\text {th }}$ week & $256.05 \pm 109.952$ & 30.79 & 0.000 \\
\hline & Pre vs $8^{\text {th }}$ week & $286.84 \pm 103.613$ & 64.21 & 0.000 \\
\hline & $4^{\text {th }}$ week vs $8^{\text {th }}$ week & $320.26 \pm 101.462$ & 33.42 & 0.000 \\
\hline \multirow[t]{3}{*}{ Control } & Pre vs $4^{\text {th }}$ week & $243.03 \pm 92.908$ & 0.79 & 0.337 \\
\hline & Pre vs $8^{\text {th }}$ week & $243.81 \pm 92.105$ & 0.65 & 0.590 \\
\hline & $4^{\text {th }}$ week vs $8^{\text {th }}$ week & $243.68 \pm 92.105$ & 0.14 & 0.864 \\
\hline
\end{tabular}

Table 4 GLM-RM test results (General Linear Model-Measured Measure) ANOVA between subject

\begin{tabular}{lcccc}
\hline \multicolumn{1}{c}{ FPEF (L/min) } & $\begin{array}{c}\text { Treatment } \\
\text { Mean } \pm \text { SD }\end{array}$ & $\begin{array}{c}\text { Control } \\
\text { Mean } \pm \text { SD }\end{array}$ & $\begin{array}{c}\text { Difference (confidence } \\
\text { interval 95 \%) }\end{array}$ & p-value \\
\hline Pretest & $256.05 \pm 109.952$ & $243.03 \pm 92.908$ & $13.02(-33.50-59.55$ & 0.579 \\
$4^{\text {th }}$ week & $286.84 \pm 103.613$ & $243.82 \pm 92.610$ & $43.02(-1.678-87.73)$ & 0.059 \\
$8^{\text {th }}$ week & $320.26 \pm 101.462$ & $243.68 \pm 92.105$ & $76.58(32.286-120.872)$ & 0.001 \\
\hline \multicolumn{2}{c}{ GLM Test $p=0.000$ (post hoc analysed) }
\end{tabular}

Characteristics of respondents by sex both in the treatment group and the control group were more than part of the female sex, namely 28 respondents $(73.7 \%)$ in the treatment group and 25 respondents $(65.8 \%)$ in the control group. In the characteristics of the education level of respondents in the treatment group more than a portion of tertiary education were 22 respondents $(57.9 \%)$ while in the control group almost half of them had junior high school education as many as 17 respondents $(44.7 \%)$. On the job characteristics of respondents in the treatment group, almost half worked as civil servants as many as 17 respondents $(39.5 \%)$ and in the control group 17 respondents $(39.5 \%)$ worked as IRTs and retirees. The characteristics of respondents based on Body Mass Index (BMI) in the treatment group were almost partially in the normal (18.624.9) and obese (25-29.9) categories of 18 respondents $(47.4 \%)$ and in the control group more than half in the fat category ( 25-29.9) 21 respondents $(55.3 \%)$. Characteristics of respondents based on family history who have asthma in the treatment group almost all have a family history that has asthma as many as 32 respondents $(84.2 \%)$ and the control group almost all have a family history of asthma as many as 34 respondents $(89.5 \%)$.

Table 2 shows that in the treatment group, the FPEF rate $(\%)$ of a small number of respondents was in the green category (80$100 \%$ compared to predictive values) which meant that breathing function was good in the pre test as many as 5 respondents $(13.2 \%)$ and the numbers tended to increase after 4 week of intervention as many as 7 respondents $(18.4 \%)$, and after 8 weeks of intervention as many as 10 respondents $(26.3 \%)$. Almost part of it is in the yellow zone category (50$80 \%$ compared to the predicted value), which means that the respiratory tract constriction starts at $17(44.7 \%)$, whose numbers tend to rise after 4 weeks of intervention by 21 respondents $(55.3 \%)$, and after 8 weeks of intervention there were 20 respondents $(52.6 \%)$. A small number of respondents were in the red category $(\leq 50 \%$ compared to predictive values) which means that there was a narrowing of the large respiratory tract in the pre test as many as 5 respondents $(13.2 \%)$ and the number tended to increase after 4 weeks of intervention by 7 respondents $(18.4 \%)$, and after 8 weeks of intervention as many as 10 respondents $(26.3 \%)$.

Table 3 In the control group, the FPEF value $(\%)$ of a small number of respondents 
Wiwik Udayani: The Effect of Combination of Buteyko Breathing Technique and Walking Exercise

was in the green category (80-100\% compared to predictive values) which meant that breathing function was good in the pre test as many as 5 respondents $(13.2 \%)$ and the numbers tended to decline after 4 weeks and after 8 weeks of evaluation 4 respondents $(10.5 \%)$. Almost part of it is in the yellow zone category $(50-80 \%$ compared to predictive value), which means it indicates a narrowing of the respiratory tract, namely in the pre test as many as 16 respondents $(42.1 \%)$, whose numbers tend to remain after 4 weeks of intervention by 18 respondents (47.4\%), and after 8 weeks of intervention there were 17 respondents $(44.7 \%)$. Almost half of the respondents were in the red category $(\leq 50 \%$ compared to the predicted value) which means that there was a narrowing of the large respiratory tract in the pre test as many as 17 respondents $(44.7 \%)$ and the numbers tended to remain after 4 weeks of intervention as many as 16 respondents $(42.1 \%)$, and after 8 weeks of intervention there were 17 respondents $(44.7 \%)$.

Table 3 The results of the GLOV-RM (General Linear Repeated Measure) ANOVA within subject showed that in the treatment group there were significant differences in FPEF before and after 4 weeks of combined training Buteyko breathing technique and walking exercises with a value of $p=0.000(p$ $<0.05)$, there were significant differences in FPEF before and after 8 weeks of combined training of Buteyko breathing techniques and walking exercises with a value of $p=0.000$, there were significant differences in FPEF between week 4 and week 8 with a value of $\mathrm{p}=0.000$. In the control group there were no significant differences in FPEF before and after 4 weeks of evaluation with $p=0.337$ ( $p$ $<0.05$ ), there were no significant differences in FPEF before and after 8 evaluations with a value of $p=0.590$, no difference in meaningful FPEF between week 4 and week 8 with the value $\mathrm{p}=0.864$.

Table 4 The GLM-RM (General Linear Model Measured) ANOVA between subject test results showed there were differences in the APEP value between the treatment group and the control group on one measurement with a value of $p=0.000$. The difference in the APEP value between the treatment group and the control group occurred in the 8th week measurement with a value of $\mathrm{p}=0.001$.

\section{Discussion}

The results showed that a combination of Buteyko breathing techniques and walking exercises affect in increasing FPEF rate (L/ minute). The increase in APEP (L / min) after 4 weeks of performing a combination of Buteyko breathing technique and walking exercises is suitable with research conducted by Utama (2018) which states that The combination Active Cycle Breathing Technique and Buteyko Therapy are given a minimum of 4 weeks of intervention with the frequency 3 times a week increases the Forced Peak Expiratory Flow and asthma control. The increase in FPE occurs simultaneously until the end of week 8. Research conducted by Juhariyah et al., (2012) which provides a combination of physical exercise and breathing exercises for 8 weeks, 5 exercises per week, each 30-minute training session is proven effective in increasing the status functional especially FPEF daily variability.

In asthma, there is an inability to reach the value of normal breathing air flow, especially in expiration, as indicated by the FPEF rate. FPEF is the achievement of maximum expiratory air flow from maximum expiration to assess the presence and severity of airway obstruction (Barnes et al., 2009). Giving physical therapy and breathing exercises is part of pulmonary rehabilitation which is expected to improve functional status, immunological status, and quality of life for asthma patients (Juhariyah et al., 2012). Physical exercise is an important component of comprehensive pulmonary rehabilitation because peripheral muscles in patients with chronic disease not only wasted but also experience changes in muscle fiber distribution and decreased metabolic capacity. Physical exercise improves endurance, improves performance of daily activities, reduces anxiety associated with shortness of breath due to activity (Celli et al., 2004; Mason et al., 2010; Juhariyah et al., 2012).

Hyperventilation that occurs in asthma can reduce levels of $\mathrm{CO} 2$ in the blood (Ritz et al., 2008; Prem et al, 2013). Research conducted by Grover and Afle (2014) stated 
that Buteyko's breathing technique can increase FEV1 (Forced Expiratory Vital in one second), FEV1 / FVC (forced Vital Capacity) and Forced Peak Expiratory Flow through a control pause mechanism that can increase $\mathrm{CO} 2$ concentration which will regulate breathing through the respiratory center in the medulla (Courtney, 2013), nasal breathing that produces nitric oxide (NO) which has bronchodilating effects, reduces breathing volume by using a combination of increased abdominal muscle and relaxation of respiratory accessory muscles, long breath can restore carbon dioxide gas exchange, cerebral vasodilation as a result of oxygen depletion and increased CO2 (Grover \& Afle, 2014).

Asthma is a chronic inflammatory disease of the airways characterized by airway obstruction and bronchial hypersensitivity (GINA, 2018). Exercises that can reduce airway hyperresponse and systemic inflammation by reducing the value of IL-6 and monocyte chemoattractan protein 1 (CMP-1) is aerobic (França-Pinto et al., 2015). Aerobic exercise that is easy to do and control is a walking exercise (Hall et al., 2017). A study conducted by Boyd et al., (2012) shows that walking exercises can improve asthma control and cardiopulmonary fitness levels without causing interference with adult asthma sufferers. Physical activity such as walking is classified as aerobic, especially for the muscles of the lower extremities which require an increase in energy requirements so that cardiorespiratory work increases with increasing heart rate and the contents of the stroke (Hall et al., 2017). Other studies have shown that aerobic exercise can increase functional capacity, FPEF, maximum inspiratory and expiratory pressure (Andrade et al. 2014), pulmonary function and VO2max (Abdelbasset et al, 2018). To prevent exercise induced asthma that occurs in physical exercise, adjustments can be made to exercise with the patient's condition and warm up before exercise (Zega, et al, 2011). If physical exercise is used as a habit, it should be easy to do without unwanted side effects to improve fitness which indirectly improves asthma (Zega, et al, 2011).

In the control group there was no difference in the FPEF value before and after the evaluation. This occurs because asthma patients who do not do regular breathing exercises can aggravate the symptoms of shortness of breath that arise during an attack because these patients do not know the correct breathing technique. This can cause ventilation-perfusion imbalance in the lungs. Breath training and physical activity or exercises that are not carried out by asthma patients have an impact on the weakness of the respiratory muscles so that there is a decrease in lung function, in addition to respiratory disorders and symptoms of shortness of breath will increase and tolerance to activity decreases (Sahat, Irawaty and Hastono, 2011).

There were differences in the FPEF values in the $8^{\text {th }}$ week measurement between the treatment group and the control group. This happens because asthma patients who exercise longer, the tolerance to exercise will increase. Increased tolerance for training can increase the value of FPEF (Sahat, Irawaty and Hastono, 2011).

\section{Conclusion}

The combination of Buteyko's breathing techniques and walking exercises is a combination of Buteyko breathing techniques and relaxing walking exercises. The findings indicate that breathing exercises and physical exercise through a combination of Buteyko breathing techniques and walking exercise can increase the FPEF rate through the mechanism of increasing $\mathrm{CO} 2$ and producing nitric oxide which has bronchodilation effects and through decreasing inflammatory mediators so that it can reduce asthma symptoms. This exercise can be used as an alternative choice in supporting pharmacological therapy to improve FPEF.

\section{References}

Adeniyi, B. O. and Erhabor, G. E. (2011) 'The peak flow meter and its use in clinical practice', African Journal of Respiratory Medicine, pp. 5-8. 
Wiwik Udayani: The Effect of Combination of Buteyko Breathing Technique and Walking Exercise

Alsubaie, S. F. (2018) 'Evaluating pulmonary function, aerobic capacity, and pediatric quality of life following a 10 -week aerobic exercise training in school-aged asthmatics : a randomized controlled trial', pp. 10151023.

Andrade, B. De et al. (2014) 'ScienceDirect The efficacy of aerobic training in improving the inflammatory component of asthmatic', Respiratory Medicine, pp. 1438-1445. doi: 10.1016/j.rmed.2014.07.009.

Barnes, P. J. et al. (2009) Asthma and COPD: basic mechanisms and clinical management. Elsevier.

Boyd, A. et al. (2012) 'Feasibility of exercising adults with asthma: a randomized pilot study', Allergy, Asthma \& Clinical Immunology, 8(1), p. 13. doi: 10.1186/17101492-8-13.

Celli, B. R. et al. (2004) 'Standards for the diagnosis and treatment of patients with COPD: a summary of the ATS/ERS position paper', European Respiratory Journal. Eur Respiratory Soc, 23(6), pp. 932-946.

Courtney, R. (2013) Buteyko breathing method. SecondEdi, Recognizing and Treating Breathing Disorders: A Multidisciplinary Approach. Second Edi. Elsevier Ltd. doi: 10.1016/B978-0-7020-4980-4.00023-X.

Dahlan, M. S. (2014). Statistik untuk Kedokteran dan Kesehatan, Deskriptif, Bivariat, dan Multivariat Dilengkapi Aplikasi dengan Menggunakan SPSS, (Statistics for Medicine and Health, Descriptive, Bivariate, and Multivariate Completed Applications Using SPSS). pp. 1-47.

Dahlan, M. S. (2013) 'Besar sampel untuk desain khusus', Dalam: Aklia S, penyunting. Besar sampel dan cara pengambilan sampel dalam penelitian kedokteran dan kesehatan. ('Sample size for custom designs', In: Aklia $\mathrm{S}$, ed. Sample size and sampling method in medical and health research). Seri evidence based medicine, 2, pp. 81-115.

Ducharme, F. M. and Hicks, G. C. (2000)
'Anti-leukotriene agents compared to inhaled corticosteroids in the management of recurrent and/or chronic asthma.', The Cochrane database of systematic reviews, (3), pp. CD002314-CD002314.

França-Pinto, A. etal.(2015) 'Aerobic training decreases bronchial hyperresponsiveness and systemic inflammation in patients with moderate or severe asthma: a randomised controlled trial', Thorax, 70(8), pp. 732-739. doi: 10.1136/thoraxjnl-2014-206070.

GINA (2018) 'Global Strategy for Asthma Management and Prevention'.

Godfrey, K. (2010) 'The Buteyko technique in asthma management', Practice nursing, 21(5), pp. 238-242. Available at: http:// www.resmedjournal.com/article/S09546111(07)00511-2/fulltext.

Grover, G. M. A. S. K. (2014) 'Gauri Mayank Afle 1 Sumeeta Khaund Grover 2', 1(3), pp. 116-119. doi: 10.15621/ijphy/2014/ v1i3/53464.

Hall, C. et al. (2017) 'Nonpharmacologic Therapy for Severe Persistent Asthma', The Journal of Allergy and Clinical Immunology: In Practice. Elsevier, 5(4), pp. 928-935. doi: 10.1016/j.jaip.2017.04.030.

Juhariyah, S. et al. (2012) 'Efektivitas Latihan Fisis dan Latihan Pernapasan pada Asma Persisten Sedang-Berat'. (The Effectiveness of Physical Exercises and Breathing Exercises on Moderate-Severe Persistent Asthma). $J$ Respir Indo, 32(1), pp. 17-24.

Masoli, M. et al. (2004) 'The global burden of asthma: executive summary of the GINA Dissemination Committee report', Allergy. Wiley Online Library, 59(5), pp. 469-478.

Mason, R. J. et al. (2010) Murray and Nadel's Textbook of Respiratory Medicine E-Book: 2-Volume Set. Elsevier Health Sciences.

Mohamed, Z., Riad, N. M. and Ahmed, F. H. (2013) 'Effect of Buteyko breathing technique on patients with bronchial asthma', 
Wiwik Udayani: The Effect of Combination of Buteyko Breathing Technique and Walking Exercise

Egyptian Journal of Chest Diseases and Tuberculosis. The Egyptian Society of Chest Diseases and Tuberculosis, 61(4), pp. 235241. doi: 10.1016/j.ejcdt.2012.08.006.

Pakhale, S. et al. (2013) 'Effect of physical training on airway inflammation in bronchial asthma: A systematic review', BMC Pulmonary Medicine. BMC Pulmonary Medicine, 13(1), p. 1. doi: 10.1186/14712466-13-38.

Phillips, S. (2014) Global Asthma Report 2014. Available at: http://www. globalasthmanetwork.org/news/GAR2014. php (Accessed: 26 September 2018).

Prem, V., Sahoo, R. C. and Adhikari, P. (2013) 'Comparison of the effects of Buteyko and pranayama breathing techniques on quality of life in patients with asthma A randomized controlled trial', Clinical Rehabilitation, 27(2), pp. 133-141. doi: $10.1177 / 0269215512450521$.

Renolleau-Courtois, D. et al. (2014) 'Homebased respiratory rehabilitation in adult patients with moderate or severe persistent asthma', Journal of Asthma, 51(5), pp. 552558. doi: 10.3109/02770903.2014.885039.

Ritz, T. et al. (2008) 'Hyperventilation symptoms are linked to a lower perceived health in asthma patients', Annals of Behavioral Medicine. Oxford University
Press, 35(1), pp. 97-104.

Sahat, C. S., Irawaty, D. and Hastono, S. P. (2011) 'Peningkatan kekuatan otot pernapasan dan fungsi paru melalui senam asma pada pasien asma'. (Increased respiratory muscle strength and lung function through asthma exercises in asthmatic patients). Jurnal Keperawatan Indonesia, 14, pp. 101-106.

Utama, J. E. P. (2018) 'Kombinasi Active Cycle Breathing Technique Dan Buteyko Therapy Terhadap Pefr Dan Kontrol Asma Di Puskesmas Kedungkandang Dan Puskesmas Kendalsari Kota MalanG'. (Combination of Active Cycle Breathing Technique and Buteyko Therapy for Pefr and Asthma Control in Kedungkandang Health Center and Kendalsari Health Center, Malang City). Univeritas Airlangga.

'WHO | Asthma' (2013) WHO. World Health Organization. Available at: http://www.who. int/respiratory/asthma/en/ (Accessed: 26 September 2018).

Zega, C. T. A., Yunus, F. and Wiyono, W. H. (2011) 'Perbandingan manfaat klinis senam merpati putih dengan senam asma Indonesia pada penyandang asma'. (Comparison of the clinical benefits of Merpati Putih Exercise with Indonesian asthma exercises for people with asthma). Jurnal respirologi indonesia, 31(2), pp. 72-80. 